УДК 621.382

\title{
УСОВЕРШЕНСТВОВАННАЯ ЯЧЕЙКА SRАМ С БОЛЬШИМ СТАТИЧЕСКИМ ЗАПАСОМ ПОМЕХОУСТОЙЧИВОСТИ И ПОВЫШЕННОЙ СТАБИЛЬНОСТЬЮ С ПРИМЕНЕНИЕМ МЕМРИСТОРОВ 45-НМ ТЕХНОЛОГИИ*
}

\author{
ШІ. СИНГХ, В. МИШРА \\ ITМ университет, \\ Индия, Гвалиор
}

\begin{abstract}
Аннотация. Технология сверхбольших интегральных схем VLSI (very large scale integrated) завоевала популярность благодаря возможности значительного изменения и адаптации. Развитие данных платформ идет по пути уменьшения размеров элементов. Но происходит не только уменьшение размеров, но и революция в конструировании, когда все схемы переключаются с уровня единичных элементов к уровню других появляющихся устройств. В этой борьбе мемристоры более способны закрепится в области VLSI по сравнению с другими новыми устройствами. В данной работе представлено изучение статического запаса помехоустойчивости, подчеркивается новая проблема точности, поскольку шум оказывает большое влияние на напряжение удержания ячейки SRAM и это влияние в мемристорной ячейке меньше, чем для традиционной ячейки 7T SRAM. Результаты имитационного моделирования представлены для ячейки 7T SRAM и мемристорной 7T SRAM ячейки технологии 45 нм. В данной работе обсуждается и сравнивается влияние коэффициентов ячейки и нагрузки.
\end{abstract}

Ключевые слова: напряжение шума; RSNM; WSNM; коэффициент ячейки; коэффициент нагрузки; мемристор; ячейка 7T SRAM

\section{1. ВВЕДЕНИЕ}

Технология комплиментарных транзисторов метал-оксид-полупроводник $\mathrm{CMOS}$ (complementary metal oxide semiconductor, КМОП) сталкивается с существенными проблемами при размерах канала менее 45 нм. Это такие проблемы, как подпороговые токи утечки, влияние горячих носителей заряда, несоответствие устройств и ухудшение подвижности носителей заряда. В этой борьбе транзисторы с множеством затворов решают эти проблемы CMOS c монолитной подложкой. Очевидно, что материалы последующей технологии должны показывать высокую стабильность, подвижность, масштабируемость и уменьшение влияния укороченного канала по отношению к вариациям техпроцесса.

Мемристоры сейчас являются многообещающими устройствами для разработчиков, поскольку обладают множеством необходимых свойств. Они компактны, занимают небольшую площадь, имеют малую потребляемую мощность и малые токи утечки. В дополнение к этим свойствам мемристоры делают систему энергонезависимой, поскольку мемристоры имеют энергонезависимую природу,

* Работа выполнена при поддержке ITM University (Gwalior) в сотрудничестве с Cadence Design System (Bangalore).

DOI: $10.20535 / \mathrm{S} 0021347018050035$

(๑). Сингх, В. Мишра, 2018 


\section{БИБЛИОГРАФИЧЕСКИЙ СПИСОК}

1. Bowman, K. A.; Duvall, S. G.; Meindl, J. D. "Impact of die-to-die and within-die parameter fluctuations on the maximum clock frequency distribution for gigascale integration," IEEE J. Solid-State Circuits, Vol. 37, No. 2, P. 183-190, Feb. 2002. DOI: 10.1109/ 4.982424.

2. Borkar, S.; Karnik, T.; Narendra, S.; Tschanz, J.; Keshavarzi, A.; De, V. "Parameter variations and impact on circuits and microarchitecture," Proc. of 40th Annual Design Automation Conf., 2-6 Jun. 2003, Anaheim, CA, USA. ACM, 2006, pp. 338-342. DOI: 10.1145/775832. $\underline{775920 .}$.

3. Karnik, T.; De, V.; Borkar, S. "Statistical design for variation tolerance: key to continued Moore's law," Proc. of Int. Conf. on Integrated Circuit Design and Technology, 17-20 May 2004, Austin, TX, USA. IEEE, 2004, pp. 175-176. DOI: 10.1109/ICICDT.2004.1309939.

Поступила в редакцию 17.11.2015
4. Doyle, S.; Ramaswamy, S.; Hoang, T.; Rockett, L.; Grembowski, T.; Bumgarner, A. "High performance radiation hardened static random access memory (SRAM) design for space applications," Proc. of IEEE Aerospace Conf., 6-13 Mar. 2004, Big Sky, MT, USA. IEEE, 2004, pp. 2284-2293. DOI: 10.1109/AERO.2004.1368022.

5. Chua, L. "Memristor-The missing circuit element,“ IEEE Trans. Circuit Syst., Vol. 18, No. 5, P. 507-519, 1971. DOI: 10.1109/TCT.1971.1083337.

6. Strukov, D. B.; Snider, G. S.; Stewart, D. R.; Williams, R. Stanley. "The missing memristor found," Nature, Vol. 453, P. 80-83, 2008. DOI: 10.1038/nature 06932.

7. Itoh, M.; Chua, L. O. "Memristor oscillators," Int. J. Bifurcation Chaos, Vol. 18, No. 11, P. 3183-3206, 2008. DOI: $10.1142 / \mathrm{S} 0218127408022354$.

8. Mukherjee, Debasis; Mondal, Hemanta Kr.; Reddy, B. V. R. "Static noise margin analysis of SRAM cell for high speed application," Int. J. Computer Science Issues, Vol. 7, No. 5, Sept. 2010. URI: https://www.ijcsi.org/ papers/7-5-175-180.pdf.

9. Chandrakasan, A. P.; Sheng, S.; Brodersen, R. W "Low-power CMOS digital design," IEEE J. Solid-State Circuits, Vol. 27, No. 4, P. 473-484, Apr. 1992. DOI: 10.1109/4.126534.

10. Pavlov, Andrei; Sachdev, Manoj. CMOS SRAM Circuit Design and Parametric Test in Nano-Scaled Technologies. Springer, 2008. DOI: 10.1007/978-1-40208363-1.

11. Kang, Sung-Mo; Leblebici, Yusuf. CMOS Digital Integrated Circuits: Analysis \& Design, 3rd ed. McGraw-Hill Education, 2002.

12. Singh, Shalini; Sable, Varun; Baghel, Vijay Singh; Akashe, Shyam. "Memory device with non-volatile memory array including one FinFET one memristor (1F1M)," Ref. No. 3093/MUM/2015, Pub. 11 Sept. 2015, India.

13. Rabaey, Jan M.; Chandrakasan, Anantha; Nikolic, Borivoje. Digital Integrated Circuits, 2nd ed. Pearson, 2003. 